\title{
Inapparent Chlamydial Infection in the Urogenital Tract of Guinea-pigs
}

\author{
By G. OZANNE† AND J. H. PEARCE* \\ Department of Microbiology, University of Birmingham, Birmingham B15 2TT
}

(Received 11 March 1980)

\begin{abstract}
Microbiologically inapparent urogenital infection appeared to be induced in male guineapigs inoculated intra-urethrally with low doses of the guinea-pig inclusion conjunctivitis strain (GP-IC) of Chlamydia psittaci. This state was indicated by the ability of inoculated animals to donate eye infection to normal animals caged with them. Donors failed to develop overt urogenital infection throughout the period of transmission judged by both absence of infected cells in urethral scrapings and failure to isolate GP-IC in cell culture; however, inoculation of donors with 5-iododeoxyuridine led to transient appearance of infectivity in scrapings. In distinction from overtly infected animals, donors failed to develop serum antibody and remained susceptible to urethral challenge with larger doses of GP-IC. Animals that had recovered from overt urethral infection were resistant to challenge and appeared unable to transmit eye infection.
\end{abstract}

\section{INTRODUCTION}

Recent epidemiological research has strongly implicated Chlamydia trachomatis as a major cause of sexually transmitted infection in man (Schachter, 1978). The possibility has been raised that urogenital tract infection may show features of latency and reactivation (Richmond \& Clarke, 1977). Latency in chlamydial infection has been defined as persistence of organisms without obvious harm to the host; organisms may either be excreted and infect new hosts or may possibly be present in the latently infected host in a non-infectious state or one that has an extremely low infectivity (Storz, 1971). The latter would be difficult to detect in affected patients.

Latent chlamydial infection of the urogenital tract has not so far been reported in laboratory or domestic animals. Nor have there been any systematic studies of the mechanism of latency, which, as defined, may embrace two distinct situations. In one, the host shows a shedding 'carrier' state, possibly controlled by the immune response; in the other, organisms are harboured in a predominantly dormant, non-multiplying form, probably resulting from nutrient limitation, as observed in cell culture (Hatch, 1975). It has been questioned whether the latter state does occur in vivo (Schachter, 1978).

Investigation of these alternatives would be feasible with a suitable animal model. The guinea-pig inclusion conjunctivitis strain (GP-IC) of Chlamydia psittaci which causes conjunctival and genital infection in guinea-pigs has proved of increasing interest as a nonprimate model for C. trachomatis infections in man (Mount et al., 1972; Murray et al., 1973; Nichols et al., 1978; Barron et al., 1979). We now present evidence that GP-IC can cause microbiologically inapparent infection of the urethra in male guinea-pigs which can be

$\uparrow$ Present address: Department of Microbiology and Immunology, Faculty of Medicine, University of Montreal, Montreal, P.Q. H3C 3J7, Canada. 
transiently activated by drug treatment. Such a state may have relevance for study of chlamydial latency; a preliminary account of the work has been published (Ozanne \& Pearce, 1979).

\section{METHODS}

Organism. The guinea-pig inclusion conjunctivitis strain of Chlamydia psittaci was grown in eggs, harvested, purified and stored as previously described (Allan \& Pearce, 1979); the purified suspension represented a 20 -fold concentration of organisms in undiluted crude yolk-sac suspension and contained $2.1 \times 10^{9}$ inclusion-forming units $\mathrm{ml}^{-1}$ by titration in irradiated McCoy cell monolayers with addition of cycloheximide (Allan et al., 1979), $2.4 \times 10^{\circ} 50 \%$ egg lethal doses $\left(\mathrm{ELD}_{50}\right)$ by titration in chick embryos (Moore et al., 1974) and $4.3 \times 10^{9}$ particles $\mathrm{ml}^{-1}$ by the method of Reeve \& Taverne (1962). Stock preparations of GP-IC grown in irradiated McCoy cells (cell-grown organisms; Allan \& Pearce, 1979) and the guinea-pig conjunctiva (guinea-pig-grown organisms; Allan et al., 1979) were kindly provided by S. Ainsworth (Department of Microbiology, University of Birmingham) and had been titrated for infectivity in chick embryos. In experimental infection of guinea-pigs, inocula were guinea-pig-grown organisms except where stated.

Guinea-pigs. These were of the Dunkin-Hartley strain and were bred in this Department. Animals were used 4 to 5 weeks post weaning; their weights ranged from 450 to $800 \mathrm{~g}$; male animals receiving intraurethral inocula were $550 \mathrm{~g}$ or greater in weight.

Experimental infection. Female guinea-pigs were inoculated with cell-grown GP-IC intra-vaginally (Mount et al., 1972) following rupture of the vaginal closure membrane during oestrus. Using a $50 \mu 1$ microsyringe (Hamilton Bonaduz, Switzerland) $20 \mu \mathrm{l}$ of inoculum was injected. Male guinea-pigs were inoculated with guinea-pig-grown GP-IC intra-urethrally under general anaesthesia with pentobarbitone sodium (Sagatal; May \& Baker, Dagenham, Essex). A microsyringe was introduced into the extruded penis to a distance of $5 \mathrm{~mm}$ and a total of $15 \mu \mathrm{l}$ of inoculum was delivered in $3 \mu \mathrm{l}$ portions with $30 \mathrm{~s}$ intervals of massage of the penis by lateral and rolling pressure with the fingers to facilitate dispersion of the organisms and avoid expulsion of the inoculum.

Examination of inoculated animals. For animals in which development of conjunctival infection was anticipated both eyes were examined daily for clinical signs of conjunctivitis. At the first indication of slight hyperaemia or other signs (Kazdan et al., 1967) one drop of local anaesthetic [sterile $1 \%$ (w/v) solution of Amethocaine hydrochloride; Smith \& Nephew Pharmaceuticals, Welwyn Garden City, Herts.] was applied to the eye and the upper tarsal conjunctiva (Treharne, 1971) was gently scraped with a nichrome spatula; the scrape was assayed for GP-IC infectivity (see below). Subsequent scrapes were taken in duplicate at $3 \mathrm{~d}$ intervals while signs of infection remained; scrapes were smeared on to microscope slides with 1 drop of phosphate buffer, $\mathrm{pH} 7 \cdot 2$, and stained with Giemsa and with fluorescent label by the method of Woodland et al. (1978) using rabbit antiserum to egg-grown GP-IC and FITC-conjugated swine anti-rabbit immunoglobulin (Nordic Immunological Labs, Tilburg, Holland). Rhodamine-labelled bovine albumin was applied as counter-stain (Treharne, 1971) and the smears were examined microscopically for the presence of intracytoplasmic inclusions.

After intra-vaginal inoculation, animals were scraped with a nichrome spatula at $3 \mathrm{~d}$ intervals during oestrus and the smears were stained with Giemsa and examined for the presence of inclusions.

After intra-urethral inoculation of male guinea-pigs, urethral scrapes were taken under general anaesthesia at stated times. During the period when overt infection was expected to develop the urethra was scraped with a sterile, disposable $1 \mu \mathrm{l}$ plastic loop (Gibco-Biocult, Paisley, Renfrewshire) and smears were examined microscopically after fluorescence staining; with this procedure the majority of samples contained 100 to 300 epithelial cells which could be counted to assess the proportion of infected cells. In certain experiments inoculated male guinea-pigs were assessed for possible delayed appearance of infected cells in the urethra. Under anaesthesia the urethra was scraped with a lachrymal curette (spoon diam. $2 \mathrm{~mm}$; John Weiss, London) and assayed for infectivity; this procedure gave a minimum of 150 cells per sample; bleeding of the urethra occurred in about $10 \%$ of scrapes.

Detection of infectivity in mucosal scrapes. Conjunctival and urethral scrapes were suspended immediately in $1 \mathrm{ml}$ chilled phosphate buffer, $\mathrm{pH} \mathrm{7.2,} \mathrm{containing} \mathrm{streptomycin} \mathrm{and} \mathrm{vancomycin} \mathrm{(each} \mathrm{at} 0.5 \mathrm{mg} \mathrm{ml}^{-1}$ ) and held for up to $2 \mathrm{~h}$. The chilled suspension was sonicated for $30 \mathrm{~s}$ (Rapidis $180,75 \mathrm{~W}, 3 \mathrm{~mm}$ tip; Ultrasonics

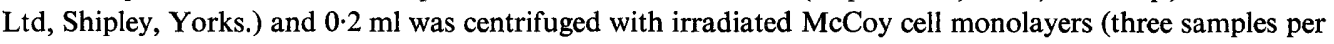
suspension) by the conventional assay procedure of Allan et al. (1979). In one experiment the technique of centrifuge-assisted secondary infection was applied (Allan et al., 1979) in which inoculated monolayers were recentrifuged $40 \mathrm{~h}$ later so that organisms released in the first cycle of infection could infect the remaining, largely uninfected, cells. In all experiments the entire monolayer was scanned microscopically for the presence of inclusions at $500 \times$ magnification. 
Collection of serum and urine and titration of antibody. Blood was taken from anaesthetized guinea-pigs by cardiac puncture both before and about 4 weeks after inoculation with GP-IC. At the later time urine samples were obtained from intra-urethrally inoculated animals under general anaesthesia. Urine was collected in a sterile plastic bottle from the extruded penis while gentle intermittent pressure was applied to the abdomen. In most instances urine was obtained at the first time of sampling, normally in the afternoon after feeding and watering in the morning; occasionally samples were obtained 1 or $2 \mathrm{~d}$ later.

Serum and urine samples were stored at $-20^{\circ} \mathrm{C}$ until titrated for antibody by the indirect micro-immunofluorescence method (Wang, 1971) as used for GP-IC (Murray et al., 1973) with minor modification (S. Ainsworth \& J. H. Pearce, unpublished results). The slide antigen was egg-grown GP-IC purified by Renografin (Allan \& Pearce, 1979) and serum or urine dilutions were made in phosphate buffer, pH $7 \cdot 2$. Serum antibody was detected by addition of FITC-conjugated swine anti-guinea-pig immunoglobulin (Nordic Immunological Labs), and sIgA antibody in urine by addition of rabbit antiserum to guinea-pig secretory piece (the antiserum was a gift from Dr D. Catty, Department of Immunology, University of Birmingham) and FITCconjugated swine anti-rabbit immunoglobulin. Samples of normal serum, urine and tears and of immune serum and tears from animals recovered from conjunctival infection (a source of $\operatorname{sgA}$ antibody) were always titrated in parallel.

\section{RESULTS AND DISCUSSION}

Response of male guinea-pigs to urethral inoculation of GP-IC

Animals receiving the highest doses of GP-IC $\left(10^{5} \mathrm{ELD}_{50}\right)$ became heavily infected $7 \mathrm{~d}$ later and remained infected until at least day 15 (Table 1). At lower doses animals showed overt infection over the same period but with decreasing numbers of infected cells. By calculation (Reed \& Muench, 1938) the dose to infect $50 \%$ of animals (ID 50 ) was $2 \times 10^{3}$ $\mathrm{ELD}_{50}$. Large numbers of neutrophil polymorphonuclear leucocytes (5 PMN per epithelial cell) were seen in smears at the peak of infection; occasional PMN (1 PMN per 40 epithelial cells) were seen in urethral scrapings from animals which had not developed overt infection.

All overtly infected animals developed antibodies in serum as determined by microimmunofluorescence titration on sera at day 24 ; titres varied from 1:4 to 1:64. Interestingly, undiluted urine samples from these animals (days 25 to 28 ) appeared to be positive for sIgA antibody by the micro-immunofluorescence test (see Methods); this was never observed in urine from normal or inoculated animals that had failed to become infected.

\section{Persistence of GP-IC in non-responding animals after urogenital inoculation}

Preliminary results. Female guinea-pigs which had been caged singly were inoculated intra-vaginally with $10^{3}, 10^{2}$ or 10 ELD $_{50}$ (three animals per dose) of GP-IC grown in McCoy cell monolayers. Only animals given the highest dose became overtly infected, judged by the appearance of inflammatory and infected epithelial cells in vaginal scrapings and the

\section{Table 1. Infectious response of male guinea-pigs inoculated intra-urethrally with GP-IC}

The results are combined from three experiments. Values for the percentage of infected cells in smears of urethral scrapings are means for infected animals in each group receiving a given dose.

\begin{tabular}{|c|c|c|c|c|c|c|c|}
\hline \multirow{2}{*}{$\begin{array}{c}\text { Dose } \\
\left(\operatorname{ELD}_{50}\right)\end{array}$} & \multicolumn{6}{|c|}{ Percentage of infected cells in smears on different days after inoculation } & \multirow{2}{*}{$\begin{array}{l}\text { Infected/ } \\
\text { inoculated } \\
\text { animals }\end{array}$} \\
\hline & day 4 & day 7 & day 10 & day 15 & day 18 & day 20 & \\
\hline $10^{5}$ & - & 12 & 11 & 2 & - & - & $2 / 2$ \\
\hline $3 \times 10^{4}$ & - & 12 & 6 & 1 & - & - & $2 / 2$ \\
\hline $10^{4}$ & - & 12 & 11 & 5 & _- & - & $3 / 5$ \\
\hline $3 \times 10^{3}$ & - & 9 & 4 & 2 & - & - & $3 / 4$ \\
\hline $10^{3}$ & - & 6 & 13 & 4 & - & - & $2 / 7$ \\
\hline $3 \times 10^{2}$ & - & - & 4 & 0.4 & 一 & - & $2 / 5$ \\
\hline $10^{2}$ & - & - & - & - & - & - & $0 / 3$ \\
\hline $3 \times 10^{1}$ & - & $\ldots$ & - & - & - & - & $0 / 3$ \\
\hline
\end{tabular}

-, No infected cells seen in the whole smear. 
Table 2. Development of eye infection and urethral response to drug treatment in guinea-pigs caged together after failing to respond to intra-urethral inoculation of GP-IC Inoculated non-responding guinea-pigs were caged together and groups were examined daily for
signs of eye infection; positive signs were invariably confirmed by isolation of organisms in mono-
layers inoculated with conjunctival scrapings. In experiment 1, hydrocortisone was injected intra-
muscularly ( $50 \mathrm{mg}$ per animal) on days 53,60 and 62 and urethral scrapings were taken on days
56,62 and 66 and inoculated on to monolayers. In experiment 2 , methotrexate (group a; $5 \mathrm{mg}$ per
animal, daily) or IUDR (group b; $2 \mathrm{mg}$ per animal, daily) was given intra-muscularly on days 32
to 36 and urethral scrapings were taken on days $38,39,42$ and 43 and inoculated on to monolayers.
Animals were caged together on day 21 (expt 1) or on day 29 (expt 2).

\begin{tabular}{|c|c|c|c|}
\hline $\begin{array}{l}\text { Expt no. } \\
\text { (group size) }\end{array}$ & $\begin{array}{c}\text { GP-IC } \\
\text { dose } \\
\left(\mathrm{ELD}_{50}\right)\end{array}$ & $\begin{array}{l}\text { Day on which } \\
\text { signs of eye } \\
\text { infection were } \\
\text { first apparent }\end{array}$ & $\begin{array}{l}\text { Day(s) on which } \\
\text { infectivity in } \\
\text { urethral scrapings } \\
\text { was recovered }\end{array}$ \\
\hline 1 (2) & $10^{3}$ & $\begin{array}{l}36 \\
32\end{array}$ & $\overline{56}$ \\
\hline 1 (2) & $3 \times 10^{2}$ & - & - \\
\hline 1 (2) & $10^{2}$ & - & - \\
\hline 1 (2) & 30 & - & - \\
\hline $2 a(3)$ & $\begin{array}{c}10^{4} \\
10^{3} \\
\text { Normal }\end{array}$ & $\begin{array}{l}\overline{43} \\
40\end{array}$ & - \\
\hline $2 b(3)$ & $\begin{array}{r}10^{4} \\
3 \times 10^{3} \\
10^{3}\end{array}$ & $\begin{array}{l}53 \\
-* \\
-\end{array}$ & $\begin{array}{c}39,42,43 \\
39 \\
-\end{array}$ \\
\hline
\end{tabular}

presence of antibody in serum $28 \mathrm{~d}$ after inoculation. To conserve cage space, animals within an inoculum group were then caged together at day 30 . During days 55 to 58 all three animals in the group given $10^{2} \mathrm{ELD}_{50}$, and which apparently had not been vaginally infected, developed eye infections.

No instance of sporadic eye infection or formation of antibody had previously been observed in the herd during breeding over 4 years, nor had eye infections ever developed in normal animals caged together, post weaning, and held in the room used for experimental work. It seemed unlikely that the eye infections could have developed after systemic spread of GP-IC from the urethra without evocation of serum antibody. Another possibility was that microbiologically inapparent infection had been initiated in the vagina which led subsequently to shedding of organisms and cross-infection of the eyes of other animals after caging together. On this hypothesis, the development of eye infection in the three animals could be ascribed to cross-transmission between all three acting as donors via genital-to-eye contact; transmission of eye infection to females can occur from males with overt urethral infection (Lamont et al., 1978). Alternatively, once genital transmission of eye infection to another animal occurred, others in the group might have acquired eye infection by eye-toeye contact. Absence of eye infection in the group given $10^{3} \mathrm{ELD}_{50}$ could be ascribed to failure to develop a shedding state; the dose of $10 \mathrm{ELD}_{50}$ presumably set up no infection.

Experiments in male guinea-pigs. Similar results were obtained for males inoculated intraurethrally with GP-IC. In one experiment, overt urethral infection was not detected in any animal; however, after pairs of animals which had been given the same urethral dose were 
caged together, eye infections developed 11 to $15 \mathrm{~d}$ later in both animals receiving $10^{3} \mathrm{ELD}_{50}$; no eye infections occurred in the other groups (Table 2, expt 1). In an attempt to activate urethral infection from the putatively latent state, hydrocortisone was given intra-muscularly to all animals and, to test for the presence of infective organisms, urethral scrapings were inoculated on to cell monolayers. One of the two animals with previous eye infection gave positive scrapings on one occasion; the remainder were negative throughout (Table 2 , expt 1).

In a second experiment, five animals that were part of a series given graded doses of GP-IC intra-urethrally did not develop infection and were negative for serum antibody $23 \mathrm{~d}$ later. At day 29 they were caged in groups of three and two, one normal animal was added to the latter group and the effect of drug treatment on the activation of urethral infection was then assessed. 5-Iododeoxyuridine (IUDR) induced transient infectivity in urethral scrapes from two out of three animals; methotrexate was without effect (Table 2, expt 2). However, in the group given methotrexate, eye infection developed in two animals, occurring first in the normal animal present. Eye infection developed in one of the three animals of the group given IUDR (Table 2, expt 2).

The hypothesis that microbiologically inapparent urethral infection had been initiated, with subsequent shedding of organisms, was supported by the development of eye infection in further animals coupled with transient recovery of infectious organisms from the urethra following drug treatment. That infection developed first in a normal animal within a group was consistent with the idea that eye infections resulted from cross-transmission (from donor to acceptor) and not from auto-infection developing after systemic spread from the urethra.

\section{Transmission of eye infection by non-responding animals after urethral inoculation}

In this experiment we tested the hypothesis that shedding of organisms by inapparently infected 'donors' could result in transmission of eye infection to normal animals. Potential donors were obtained by intra-urethral inoculation of male guinea-pigs with $1.5 \times 10^{3}$ ELD $_{50}$ of GP-IC. Eight of 18 inoculated male guinea-pigs showed overt urethral infection by the criteria of infected cells in urethral scrapes examined by both Giemsa and fluorescence staining 10 and $15 \mathrm{~d}$ later. Of these, six animals retained infective organisms in the urethra at day 22, all eight were clear at day 29 (urethral scrapings inoculated on to monolayers) and all eight animals showed serum antibody (titres $1: 16$ to $1: 64$ ) with possible sIgA antibody in undiluted urine at days 24 or 25 . Of the remaining ten animals, nine were negative in all respects and one was positive only with undiluted serum.

Twenty-five days after inoculation with GP-IC eight of the nine negative animals were examined for their capacity to act as donors of eye infection. Six were caged singly with two normal animals per cage and two were caged together with two normal animals in order to parallel previous experiments in which at least two potential donors had always been present in one cage.

At day 36 conjunctival scrapings taken from all animals were negative for GP-IC infectivity when inoculated on to cell monolayers; in the two previous experiments with male guinea-pigs this was about the time when transmission of eye infection became evident (see Table 2). By day 43 signs of eye infection had developed in three normal animals (three groups; Table 3 ) and only these yielded infective organisms in conjunctival scrapings taken from all animals on that day and inoculated on to monolayers. The correlation accorded with general experience in the laboratory that, during a primary infection of guinea-pigs with GP-IC, recovery of infectivity in scrapings was associated with clinical signs of eye disease. Eye infection developed in a fourth group during IUDR treatment and subsequently in a fifth group; that containing two potential donors did not behave differently from the others. In all five groups infection occurred first in a normal animal (Table 3) and 6 to $9 \mathrm{~d}$ later had spread to other animals in the groups; the hypothesis that shedding of GP-IC could lead to eye infection in other animals was therefore sustained. 
Table 3. Development of eye infection on caging 'potential donor' with normal 'acceptor' guinea-pigs

Guinea-pigs not responding to urethral inoculation of GP-IC, and thereby 'potential donors' of eye infection, were caged $25 \mathrm{~d}$ later with normal 'acceptor' animals. All animals were examined daily for signs of eye infection; the Table shows the first day when signs were detected in the left (L) or right $(\mathrm{R})$ eye. Positive signs were invariably confirmed by isolation of organisms in monolayers inoculated with conjunctival scrapings. IUDR was injected intra-muscularly into donors ( $2 \mathrm{mg}$ per animal, daily) on days 48 to 52 . In two of the groups of animals no eye infection was detected at any stage (results not shown).

\begin{tabular}{|c|c|c|c|}
\hline \multirow[b]{2}{*}{$\begin{array}{l}\text { Animal grouping } \\
\text { and status* }\end{array}$} & \multicolumn{3}{|c|}{ Day on which signs of eye infection were first apparent } \\
\hline & $\begin{array}{c}\text { Period } \\
\text { before IUDR } \\
\text { (days 26-47) }\end{array}$ & $\begin{array}{c}\text { Period } \\
\text { during IUDR } \\
\text { (days 48-52) }\end{array}$ & $\begin{array}{c}\text { Period } \\
\text { after IUDR } \\
\text { (days 53-65) }\end{array}$ \\
\hline $\begin{array}{l}\text { D } \\
\text { NA } \\
\text { NA }\end{array}$ & $\frac{-}{L, 40}$ & $\stackrel{\mathrm{L}, 49}{-}$ & $\begin{array}{r}\mathrm{R}, 53 \\
\mathrm{~L}, 54 ; \mathrm{R}, 60 \\
\mathrm{R}, 53\end{array}$ \\
\hline $\begin{array}{l}\text { D } \\
\text { NA } \\
\text { NA }\end{array}$ & L, 43 & $\begin{array}{c}\mathrm{R}, 51 \\
-\end{array}$ & $\begin{array}{rr}\text { L, } 57 & \\
& \text { R, } 63 \\
\text { L, } 60 ; & \text { R, } 64\end{array}$ \\
\hline $\begin{array}{l}\text { D } \\
\text { NA } \\
\text { NA }\end{array}$ & $\begin{array}{l}- \\
-\end{array}$ & $\begin{array}{l}-\bar{R}, 51 \\
\mathrm{R}, 51\end{array}$ & $\begin{array}{l}\text { L, } 63 ; \mathrm{R}, 57 \\
\mathrm{~L}, 55 \\
\mathrm{~L}, 54\end{array}$ \\
\hline $\begin{array}{l}\text { D } \\
\text { NA } \\
\text { NA }\end{array}$ & - & - & $\begin{array}{r}\mathrm{R}, 63 \\
\mathrm{~L}, 63 ; \mathrm{R}, 57 \\
\mathrm{~L}, 63 ; \mathrm{R}, 57\end{array}$ \\
\hline $\begin{array}{l}\text { D } \\
\text { D } \\
\text { NA } \\
\text { NA }\end{array}$ & $\begin{array}{c}\mathrm{R}, 47 \\
- \\
\mathrm{L}, 40\end{array}$ & $\begin{array}{l}- \\
\mathrm{R}, 50 \\
\mathrm{R}, 48\end{array}$ & $\mathrm{~L}, 53^{\mathrm{R}, 53}$ \\
\hline
\end{tabular}

- No signs of infection were apparent in either eye over the period.

*D, Donor; NA, normal acceptor.

Urethral scrapes were taken from donor animals at days 33, 43, 53, 57 and 64 and inoculated on to monolayers using the technique of centrifuge-assisted secondary infection (see Methods); these were negative throughout. IUDR treatment of donors (Table 3) thus had failed to evoke detectable GP-IC infectivity in the urethra; conceivably, it might have increased the rate of transmission of conjunctival infection. The lack of response to IUDR contrasted with the previous experiment (Table 2). A contributory factor may have been the use of glass beads and mechanical agitation for dispersal of scrapings at the critical days 53 and 57 because of breakdown of our ultrasonic disintegrator.

In this experiment all precautions had been taken to avoid transfer of GP-IC from one cage to another. Additionally, as controls, 18 normal animals were caged separately in the vicinity of the inoculated animals during days 42 to 63 and IUDR was administered, in parallel (see Table 3), on days 48 to 52 . Animals were examined daily for signs of eye infection and were negative throughout. As a further control for the possibility that stress, induced by caging animals together or through frequency of examination (Ganaway, 1976), might have converted latent to overt infection in apparently normal animal stock, two groups, each of four normal animals caged together, were examined over days 42 to 63 for eye infection and IUDR was given, as before, to three animals per group; no signs of infection were detected in any animal. 


\section{Capacity of animals to transmit eye infection after recovery from overt urethral infection}

This was examined with urethrally infected animals from the main experiment. Two groups of four guinea-pigs (two recovering from overt infection and two normal acceptor animals per cage) were caged from day 25 and observed over the next $40 \mathrm{~d}$. Despite the fact that one pair of recovered animals had had infective organisms in urethral scrapings at day 22 and might therefore still have been capable of overt transmission no signs of conjunctival infection developed within that group. In the other group, one normal animal showed signs of infection (right eye only) and occasional inclusions in fluorescence-stained smears from days 31 to 33 . The fleeting nature of this infection was wholly atypical of conjunctival infection in other animals in the present work, or in studies on immunity to conjunctival infection (S. Ainsworth \& J. H. Pearce, unpublished results) when signs of infection and appearance of inclusions were always observed over a period of 10 to $14 \mathrm{~d}$, even with minimal inocula. The acceptor animals were replaced with two other normal animals at day 42. No further eye infection occurred in either group.

It appeared that animals which had fully recovered from urethral infection did not shed organisms and transmit eye infection. Such animals were themselves susceptible to conjunctival challenge: two other recovered animals given $500 \mathrm{ELD}_{50}$ of GP-IC at day 40 developed severe eye infections beginning at days 42 and 49 and lasting for $12 \mathrm{~d}$.

\section{Susceptibility of urethrally inoculated animals to urethral challenge}

Four animals from the main experiment, and which had been caged singly throughout, were challenged urethrally at day 40 with $10^{4} \mathrm{ELD}_{50}$ of GP-IC. Two had recovered from overt infection; these were immune (no infectivity at days 43, 53, 57 and 64 in urethral scrapings inoculated on to monolayers with centrifuge-assisted secondary infection). The other two had not shown overt infection (one appeared positive for serum antibody in undiluted serum; see earlier) and were therefore potential donors of eye infection; both became infected (infectivity at days 43,53 and 57 in urethral scrapings inoculated on to monolayers with centrifuge-assisted secondary infection).

\section{General discussion}

The urethral responses observed in overt infection are similar to those reported by other workers (Mount et al., 1973; Howard et al., 1976) in respect of infected epithelial cells, presence of polymorphonuclear leucocytes and development of serum antibody. The finding of positive fluorescence for SIgA antibody in undiluted urine correlated with previous overt infection; whether this was a consequence of the infected state awaits further investigation.

The conclusion that male guinea-pigs can become inapparently infected in the urethra and shed infective organisms rests on two observations: firstly, that such guinea-pigs transmit eye infection to normal animals caged with them; secondly, that drug treatment induces transient appearance of GP-IC in the urethra. We have argued already that these eye infections are unlikely to have resulted from external contamination during handling, on the basis of previous experience. The control experiments in which animals were caged in the vicinity of overtly infected animals and the lack of response to IUDR support this view. For the same reasons it appears unlikely that eye infections were due to activation of a latent infection within the herd, whether conjunctival or genital in origin.

The inapparent infection described here can be regarded as latent only if donors are demonstrated, in further work, to be free of urogenital disease. The remarkable feature of these animals is that organisms should persist for so long at a level below that which could be detected in cell culture. Poor technique in sampling the urethra can result in low recovery of cells in urethral scrapes (Lamont et al., 1978) and, thereby, infectivity. Here, use of a lachrymal curette gave fair recovery (see Methods) but with occasional bleeding, although 
the latter did not appear to affect the results. The relative infrequency of scraping, to minimize trauma, might have led to failure to recover infectivity, especially if shedding of organisms was intermittent. Daily wash-out (Lamont et al., 1978) with blind passage of infectivity in monolayers (Allan et al., 1979) might increase the likelihood of detection, without the need for drug activation.

Mount \& Barron (1976) reported infection of the upper intestinal tract following intrarectal inoculation of GP-IC; they suggested also that ingestion of food contaminated with GP-IC could have been responsible. The gut as a source for shedding of GP-IC cannot be excluded here, although donor eyes ought then to have become infected as rapidly as those of normal animals present. The possibility of shedding from other epithelial surfaces, which might have become infected by the original inoculum, needs to be explored in future work. Infection of the bladder may have occurred, in addition to overt urethral infection, following inoculation of larger doses, and local antibody production there may have been responsible for the sIgA antibody apparently detected in urine.

It is of interest that all four guinea-pigs recovering from overt urethral infection apparently showed only brief shedding of organisms, judged by the failure of all but one normal animal to develop eye infection. Presumably the induced immune response clears organisms so that there is no residue of inapparent infection. The urethra in non-responding animals remained susceptible to infection but this is insufficient evidence that the shedding state is not accompanied by local humoral or cell-mediated immunity. However, failure to detect infective organisms in the urethra or eye of donor guinea-pigs may mean that the amount of GP-IC shed is too low to induce any local immune response; but this leaves unexplained why such infection of the urethra does not escalate to an overt state.

Induction of inapparent infection in guinea-pigs appeared primarily to be a function of inoculum size: a dose causing overt infection in about half the animals resulted in shedding in the majority of the other half (five of eight animals transmitted eye infection, Table 3 ). Whether the balance between overt and inapparent GP-IC infection is influenced by local microbial flora or disturbed by the introduction of an exogenous pathogen (Richmond \& Clarke, 1977) will be of interest to explore.

We are greatly indebted to our colleagues, I. Allan and S. Ainsworth, for valuable suggestions, criticism and provision of materials and to Dr S. J. Richmond for provoking the hypothesis. The work was supported by a project grant from the Medical Research Council. G.O. was in receipt of a post-doctoral fellowship from the Counseil de la Recherche en Santé du Québec.

\section{REFERENCES}

Allan, I. \& Pearce, J. H. (1979). Host modification of chlamydiae: differential infectivity for cell monolayers of chlamydiae grown in eggs and monolayers. Journal of General Microbiology 112, 53-59.

Allan, I., Ainsworth, S. \& Pearce, J. H. (1979). Detection of low levels of chlamydial infectivity in cycloheximide-treated cell monolayers. FEMS Microbiology Letters 5, 385-388.

Barron, A. L., White, H. J., RANK, R. G. \& SolofF, B. L. (1979). Target tissues associated with genital infection of female guinea pigs by the chlamydial agent of guinea pig inclusion conjunctivitis. Journal of Infectious Diseases 139, 60-68.

GaNAWAY, J. R. (1976). Bacterial, mycoplasma and rickettsial diseases. In The Biology of the GuineaPig, pp. 121-135. Edited by J. E. Wagner \& P. J. Manning. New York, San Francisco \& London: Academic Press.
Hatch, T. P. (1975). Competition between Chlamydia psittaci and $\mathrm{L}$ cells for host isoleucine pools: a limiting factor in chlamydial multiplication. Infection and Immunity 12, 211-220.

Howard, L. V., O'Leary, M. P. \& Nichols, R. L. (1976). Animal model studies of genital chlamydial infections. Immunity to reinfection with guinea pig inclusion conjunctivitis agent in the urethra and eye of male guinea pigs. British Journal of Venereal Diseases 52, 261-265.

KazDAN, J. J., Schachter, J. \& OKumoto, M. (1967). Inclusion conjunctivitis in the guinea pig. American Journal of Ophthalmology 64, 116124.

Lamont, H. C., Semine, D. Z., Leveille, C. \& Nichols, R. L. (1978). Immunity to vaginal reinfection in female guinea pigs infected sexually with chlamydiae of guinea pig inclusion conjunctivitis. Infection and Immunity 19, 807-813. 
Moore, J. E., Griffiths, M. S. \& Pearce, J. H. (1974). Chlamydial infection of conjunctival tissues in culture. British Journal of Experimental Pathology 55, 396-405.

MounT, D. T. \& BARRon, A. L. (1976). Intrarectal infection of guinea pigs with the agent of guinea pig inclusion conjunctivitis. Proceedings of the Society for Experimental Biology and Medicine 153, 388-391.

Mount, D. T., Bigazzi, P. E. \& Barron, A. L. (1972). Infection of genital tract and transmission of ocular infection to newborns by the agent of guinea pig inclusion conjunctivitis. Infection and Immunity 5, 921-926.

Mount, D. T., Bigazzr, P. E. \& Barron, A. L. (1973). Experimental genital infection of male guinea-pigs with the agent of guinea-pig inclusion conjunctivitis and transmission to females. Infection and Immunity 8, 925-930.

Murray, E. S., Charbonnet, L. T. \& MacDonald, A. B. (1973). Immunity to chlamydial infection of the eye. I. The role of circulatory and secretory antibodies in resistance to reinfection with guinea pig inclusion conjunctivitis. Journal of Immunology 110, 1518-1525.

Nichols R. L., Murray, E. S. \& Nisson, P. E. (1978). Use of enteric vaccines in protection against chlamydial infections of the genital tract and the eye of guinea pigs. Journal of Infectious Diseases 138, 742-746.

Ozanne, G. \& Pearce, J. H. (1979). A model for latent chlamydial infection of the urogenital tract. Journal of Medical Microbiology 12, xv.

REED, L. J. \& MUENCH, H. (1938). A simple method of estimating fifty per cent end points. American Journal of Hygiene 27, 493-497.

Reeve, P. \& TAVerne, J. (1962). A simple method for total particle counts of trachoma and inclusion blennorrhoea viruses. Nature, London 195, 923-924.

Richmond, S. J. \& Clarke, S. K. R. (1977). Problems in assigning a causative role to chlamydiae isolated in nongonococcal urethritis. In Nongonococcal Urethritis and Related Infections, pp. 43-46. Edited by D. Hobson \& K. K. Holmes. Washington, D.C.: American Society for Microbiology.

Schachter, J. (1978). Chlamydial infections. New England Journal of Medicine 298, 428-435.

Storz, J. (1971). Chlamydia and Chlamydia-induced Diseases. Springfield, Illinois: C. C. Thomas.

TrehaRne, J. D. (1971). A comparison of microbiological techniques for the detection of GP-IC agent in the conjunctiva of infected guinea pigs. In Trachoma and Related Disorders, pp. 435-444. Edited by R. L. Nichols. Amsterdam: Excerpta Medica.

WANG, S. P. (1971). A microimmunofluorescence method. Study of antibody response to TRIC organisms in mice. In Trachoma and Related Disorders, pp. 273-288. Edited by R. L. Nichols. Amsterdam: Excerpta Medica.

Woodland, R. M., El-SheikH, H., Darougar, S. \& SQutres, S. (1978). Sensitivity of immunoperoxidase and immunofluorescence staining for detecting chlamydia in conjunctival scrapings and in cell culture. Journal of Clinical Pathology 31, 1073-1077. 